\title{
Resistant starch in various starchy vegetables and the relationship with its physical and chemical characteristics
}

\author{
Nguyen Minh Thuy ${ }^{*}$ (D), Beverly Cheruto Too ${ }^{2}$, Kieu Minh Vuong ${ }^{1}$, Phan Thi Truc Lan ${ }^{1}$, Phan Thi Thanh Tuyen ${ }^{1}$, Nguyen \\ Bich Tram ${ }^{1}$, Le Thi Tuong Vy ${ }^{1}$, Le Ngoc Tuyen ${ }^{1}$, Ngo Van Tai ${ }^{1}$ \\ ${ }^{1}$ Deparment of Food Technology, College of Agriculture, Can Tho University, Can Tho, Vietnam. \\ ${ }^{2}$ Department of Food Technology, Hue University, Hue, Vietnam.
}

\begin{tabular}{l}
\hline ARTICLE INFO \\
\hline Article history: \\
Received on: June 29, 2021 \\
Accepted on: August 06, 2021 \\
Available Online: January 07, 2022 \\
\hline
\end{tabular}

Key words:

Resistant starch, amylose, swelling capacity, water absorption capacity, starchy vegetables

\begin{abstract}
Starch is a complex carbohydrate consisting of numerous glucose units joined by glycosidic bonds. According to digestibility, starch has been categorized into rapidly digestible starch that takes 20 minutes after consumption to be fully digested, slow digestible starch which takes between 20 and 120 minutes to be fully digested in the small intestines, and resistant starch (RS) which resists digestion in the small intestine and undergoes fermentation in the large intestines, hence producing beneficial products for the human health. The study was carried out to compare the contents of RS in different starchy vegetables and analyze the physicochemical properties such as moisture content, amylose content, swelling, and water absorption capacity (WAC) of the chosen food samples and explain the relationship between the physicochemical properties and RS content of the food samples. Potato starch recorded a high resistant starch content at $56.43 \%$, while corn starch was low at $2.82 \% \mathrm{RS}$. There was a positive correlation between RS and amylose content. However, there was a negative correlation between swelling capacity and WAC. The RS content of potato starch recorded the least swelling at $1.49 \mathrm{~g} / \mathrm{g}$ compared to the high value of yellow sweet potatoes of $8.47 \mathrm{~g} / \mathrm{g}$. Water absorption capacity presented a similar trend to swelling. In six out of the eight samples analyzed, a high amylose content in starchy foods was an indication of high RS in the food, attributed to its long chain and double helices it forms after gelatinization. A high RS content in foods leads to low swelling capacity and low WAC. Therefore, low swelling in potato starch indicated a high RS content.
\end{abstract}

\section{INTRODUCTION}

Resistant starch (RS) is a current topic that has attracted the attention of many researchers because of its effect on people's health as well as its functional properties in food processing. In the last decade, the focus has been directed toward the importance of $\mathrm{RS}$ in nutrition, not only for its low caloric content but also because it has physiological effects similar to dietary fiber. The rise in the cases of noncommunicable diseases in this era has been attributed to poor dietary choices by individuals among many factors. The incorporation of RS in commonly consumed foods may decrease the incidence of noncommunicable diseases. In addition to that, RS has a positive effect on the functioning of the digestive tract,

*Corresponding Author

Nguyen Minh Thuy, Deparment of Food Technology, College of Agriculture, Can Tho University, Can Tho, Vietnam.E-mail:nmthuy@ ctu.edu.vn growth of good microbial flora, and decrease in blood cholesterol and postprandial blood glucose due to low glycemic index of high RS foods [1] as well as prevention of colon cancers. Unlike fiber, RS has fine particles and a bland taste; hence, it has been used as a food ingredient with high consumer acceptability.

The majority of starchy foods are high in RS such as cereals, legumes, and tubers. RS has been categorized into five different groups based on its sources according to Dupuis et al. [2]. RS type I is physically inaccessible starch and is unavailable for digestion due to physical constraints. It is a food ingredient in a wide variety of conventional foods [1], and it is mainly found in whole or partially ground cereal grains. Type II RS is a native starch granule of selected botanical sources such as green bananas and potatoes. The intact granules cannot be gelatinized due to compact structure hindering enzymatic digestion [3]. Type III RS is retrograded amylose and starch. The linear structure of amylose 
enhances its tendency to form double helices particularly near $4^{\circ} \mathrm{C}$ with an adequate moisture content. The retrograded amylose has high gelatinization temperatures up to $170^{\circ} \mathrm{C}$ and cooking cannot dissociate it. Type IV RS is described as a group of starches that have been chemically modified (conversion, substitution, or cross-linking) and includes starches which have been etherized, esterified, or cross-bonded with chemicals in such a manner as to decrease their digestibility $[1,4,5]$. Type V RS entails starch interaction with lipids to form amylose-lipid complexes which entangles amylopectin restricting swelling of starch granules and enzyme hydrolysis. Botanical sources determine the structure and formation of RS type V. The enzyme resistance of amyloselipid complexes depends on the molecular structure of the lipid and the crystalline structure of the single helices. RS type V has potential health benefits in controlling postprandial glycemic and insulinemic responses and preventing colon cancer. RS type $\mathrm{V}$ shows the ability to reduce colon cancer development [6].

Incorporation of these high RS sources in daily food products such as noodles, bread, cookies, and tortillas may improve the health of individuals through the various benefits depicted by the RS in the human body. Therefore, the objective of this study was to determine the content of RS in some starchy food sources. The chemical and physical properties such as moisture, amylose content, swelling, and water absorption capacity (WAC) and how they affect the content of RS in the food samples were analyzed.

\section{MATERIALS AND METHODS}

\subsection{Materials}

Two sweet potato varieties (purple and yellow) were purchased from the Food Market in Can Tho city. Black beans (Phaseolus vulgaris), red kidney beans (P. vulgaris), and mung beans (Vigna radiata), corn starch, potato starch, and green bananas were bought at Mega Mart, Can Tho city.

A RS assay kit (Megazyme, Bray, Ireland) was used to measure the RS content of samples. Other materials included pancreatic $\alpha$-amylase (pancreatin, $10 \mathrm{~g}, 3$ Ceralpha units $/ \mathrm{mg}$ ), amyloglucosidase (AMG) $[12 \mathrm{ml}, 3,300 \mathrm{U} / \mathrm{ml}$, on soluble starch (or $200 \mathrm{U} / \mathrm{ml}$ on $p$-nitrophenyl $\beta$-maltoside*)], glucose peroxidase (GOPOD) reagent buffer $(50 \mathrm{ml} \mathrm{pH} 7.4), p$-hydroxybenzoic acid and sodium azide $(0.09 \% \mathrm{w} / \mathrm{v})$, GOPOD reagent enzymes (glucose oxidase and peroxidase) and 4-aminoantipyrine, freezedried powder, D-glucose standard solution $(5 \mathrm{ml}, 1.0 \mathrm{mg} / \mathrm{ml}$ in $0.2 \% \mathrm{w} / \mathrm{v}$ ) benzoic acid, and RS control. All of the chemicals used in this study were of analytical grade.

\subsection{Preparation of Samples}

The sweet potatoes were washed with tap water to remove soil, peeled and sliced into thin sheets, and then blanched for two minutes in $100^{\circ} \mathrm{C}$ water before drying in an oven at $65^{\circ} \mathrm{C}$ for 7 hours until the moisture content of the dried sample was around $6 \%-7 \%$ [7]. Green bananas were peeled and immediately placed in a sodium sulfite $\left(\mathrm{Na}_{2} \mathrm{SO}_{3}\right)$ solution with a concentration of $500 \mathrm{ppm}$ and left to soak for 30 minutes to prevent polyphenol oxidation from polymerizing the natural occurring polyphenols in the banana skin. The sliced bananas were dried at $65^{\circ} \mathrm{C}$ for 7 hours. Mung beans, black beans, and red kidney beans were also dried at $65^{\circ} \mathrm{C}$ for 4 hours. The dried samples were ground into powder and sieved through US standard mesh No. $70(212 \mu \mathrm{m})$. The sieved powder was placed in a sealed airtight container and stored at $25^{\circ} \mathrm{C}$ for further use.

\subsection{Extraction of RS}

For each sample, $100 \pm 5 \mathrm{mg}$ was weighed and placed in propylene tubes, $4 \mathrm{ml}$ of pancreatic $\alpha$-amylase $(4 \mathrm{ml}$ of $10 \mathrm{mg} /$ $\mathrm{ml})$ containing AMG $(3 \mathrm{U} / \mathrm{ml})$ was added to each tube, and the mixture was vortexed and incubated in a shaking water bath at $37^{\circ} \mathrm{C}$ for 16 hours (150 strokes/minute) to hydrolyze digestible starch. After the incubation period, the suspension was mixed with $4 \mathrm{ml}$ absolute ethanol $(99 \% \mathrm{v} / \mathrm{v})$ and vortexed to deactivate the enzymes. RS was recovered as pellets by centrifugation at $1500 \mathrm{~g}$ for 10 minutes. The supernatant was decanted into larger propylene tubes. The pellets were washed twice with $50 \%$ ethanol to remove any traces of digested starch and the supernatant was also decanted to propylene tubes according to the type of sample.

\subsection{Measurement of RS}

RS was adapted for each matrix using the Association of Official Analytical Chemists (AOAC) Official Method 2002.02 with some modifications [8]. The RS was extracted as pellets that were each dissolved $2 \mathrm{ml}$ of $2 \mathrm{M}$ Potassium hydroxide $(\mathrm{KOH})$ during vigorous stirring with a magnetic stirrer bar $(8 \times 12 \mathrm{~mm})$ in an ice water bath for 20 minutes. A sodium acetate buffer $(8 \mathrm{ml}$ of $1.2 \mathrm{M}, \mathrm{pH} 3.8)$ was added to each tube with magnetic stirring, and $0.1 \mathrm{ml} \mathrm{AMG}$ was immediately added $(3,300 \mathrm{U} / \mathrm{ml})$. The samples were mixed and placed in a water bath maintained at $50^{\circ} \mathrm{C}$ for 30 minutes. The samples with more than $10 \% \mathrm{RS}$ content were transferred into 100 $\mathrm{ml}$ volumetric flask and the volume was adjusted to $100 \mathrm{ml}$ with distilled water and mixed well. A $10 \mathrm{ml}$ aliquot of the solution was centrifuged at $1,500 \mathrm{~g}$ for 10 minutes. For samples containing lower than $10 \%$ RS, direct centrifugation of tubes was carried out at $1,500 \mathrm{~g}$ for 10 minutes. After centrifugation, aliquots $(0.1 \mathrm{ml})$ of either diluted or undiluted RS supernatants were transferred into glass test tubes $(13 \times 100 \mathrm{~mm})$.

Exactly $3.0 \mathrm{ml}$ of GOPOD reagent was added to each test tube and incubated in a water bath at $50^{\circ} \mathrm{C}$ for 20 minutes. The absorbance of each solution was measured at $510 \mathrm{~nm}$ against a reagent blank using a Beckman Coulter DU-800 spectrophotometer. Reagent blank was prepared by mixing $0.1 \mathrm{ml}$ of $0.1 \mathrm{M}$ sodium acetate buffer ( $\mathrm{pH} 4.5)$ and $3.0 \mathrm{ml}$ of GOPOD reagent. Standards were prepared by mixing D-glucose $(1 \mathrm{ml})$ with an appropriate amount of water which created a range of D-glucose standards. The $0.1 \mathrm{ml}$ of D-glucose standard $(0.1 \mathrm{ml})$ was mixed with $3.0 \mathrm{ml}$ of GOPOD to measure absorbance. RS content (\% dry weight basis) was calculated as follows:

$\mathrm{RS}$ (mg of RS/100 mg sample $)=(\mathrm{mg} / \mathrm{ml}$ obtained from calibration curve $) \times(\mathrm{ml}$ final volume $) \times(162 / 180$ factor to convert free D-glucose, as determined, to anhydro-D-glucose as occurs in starch $) \times(100 /$ moisture content of sample $)$.

\subsection{Moisture Content}

The moisture contents of the samples of mung bean powder, green bananas, red kidney beans, black beans, potato starch, yellow 
sweet potatoes powder, corn starch, and purple sweet potato powder were determined according to the method of AOAC [9].

\subsection{Amylose Content}

Amylose content was measured using the method of Ronoubigouwa et al. [10]. The absorbance was measured using a Beckman Coulter spectrophotometer and amylose content determined.

\subsection{Swelling and WAC}

The swelling capacity of the samples and WAC were determined according to the method of Nyam et al. [11].

\subsection{Statistical Analysis}

The data obtained were analyzed using the analysis of variance (ANOVA) and multiple range tests were used to determine the significant difference between samples $(p<0.05)$. The software used was STATGRAPHICS Centurion XVI. Standard deviation was calculated using the following Equation (1):

Standard deviation: $\quad S=\sqrt{\frac{1}{N-1} \sum_{i=1}^{N}\left(x_{i}-\bar{x}\right)^{2}}$

where $x_{1}, x_{2}, \ldots . ., x_{n}$ are the observed values of the sample items, $\bar{x}$ is the mean value of these observations, and $N$ is the number of observations in the sample.

\section{RESULTS AND DISCUSSION}

\subsection{Content of RS in Different Starchy Food Sources}

The RS content of the samples is presented in Table 1. The high content of RS was found in potato starch at $56.43 \%$, and green banana was second with $48.29 \%$ RS. Mung beans, purple sweet potatoes, black beans, red kidney beans, and yellow sweet potatoes had $30.47 \%$, $22.93 \%, 16.59 \%, 15.54 \%$, and $9.44 \% \mathrm{RS}$, respectively. The lowest RS content was $2.82 \%$ found in corn starch. The RS content of potato starch obtained in the current study was lower than the $79.3 \%$ by Chen et al. [12]. The RS content of green bananas in the current study was comparable with the $48.88 \%$ found by Moongngarm et al. [13]; however, these results varied slightly from a study which obtained $52.7 \%$ RS content in raw green bananas [14], as well as Englyst et al. [15], who also obtained RS content of green bananas of $54.2 \%$ which was significantly higher than the current study. For black beans, Fabbri et al. [16] found a high RS content of 31\%; however, Silva-Crystobal et al. [17] found a slightly lower result of RS in black beans of $11.4 \%$ in comparison to this study. This difference may be from varying growing conditions of black beans. Reddy et al. [18] obtained the range of RS values in red kidney beans to be between $21.27 \%$ and $42.34 \%$, and these values were significantly higher than the amount of RS in the current study. However, Moongngarm (2013) [19] found very low RS content in red kidney beans of 9.54\% when compared to the current study. Moongngarm [19] found the amount of RS in mung beans to be $2.3 \%$, while Eashwarage et al. [20] found $5.95 \%$ of RS in mung beans; these results were also low compared to the results in the current study. The difference in RS content may have been brought by different methods used in the measurement of RS and varied growing regions of the beans. Two studies found the native purple sweet potatoes to have $5.02 \%$ [21] and 3.06\% [22] RS content, which were quite low compared to the current study $(22.93 \%)$. In a general preview, the content of RS in five cultivars of sweet potatoes ranged between $13.2 \%$ and $17.2 \%$ [23]. However, in a different study carried out in Korea, the RS contents of sweet potato starches ranged from $1.76 \%$ in Pungwonmi to $30.75 \%$ in Jeonmi [24]; these results were in tandem with the RS content of both yellow sweet potatoes and purple sweet potatoes. For a corn starch sample, a study by Chen et al. [12] found $7.83 \%$ RS which was very high compared to the current study with $2.82 \%$ RS but another study found lower RS content of corn starch from normal corn of $0.8 \%$ [25] and finally Raigond et al. [26] mentioned RS content of normal corn starch to be $1.5 \%$ before extrusion and it increased to $2.8 \%$ after extrusion.

Differences in RS content among starches from various botanical sources were brought by not only chemical differences but also physical or structural characteristics such as granule shape and size, crystallinity pattern, molecular interaction, and arrangement [27]. High RS content in food is a desirable property as it exhibits functional properties as well as physiological health benefits $[1,28]$.

\subsection{Moisture Content}

The moisture content of samples affects RS content in the sample. There was similarity between the moisture content of yellow sweet potatoes and potato starch, however, they were significantly different from moisture content of purple sweet potatoes and mung bean (Table 1). Yellow sweet potatoes had the highest moisture content of $16.7 \%$, followed by potato starch at $14.72 \%$, yellow sweet potatoes had $11.86 \%$, red kidney beans had $10.34 \%$, and black beans, corn

Table 1: RS, amylose, and moisture contents of starchy foods.

\begin{tabular}{ccccc} 
& Sample & RS content (\%) & Amylose content (\%) & Moisture content (\%) \\
1. & Corn starch & $2.82 \pm 0.00^{\mathrm{a}}$ & $24.73 \pm 0.63^{\mathrm{a}}$ & $9.46 \pm 0.05^{\mathrm{ab}}$ \\
2. & Yellow sweet potatoes & $9.44 \pm 1.87^{\mathrm{b}}$ & $20.04 \pm 0.08^{\mathrm{b}}$ & $16.7 \pm 0.05^{\mathrm{b}}$ \\
$\mathbf{3 .}$ & Red kidney beans & $15.54 \pm 0.51^{\mathrm{c}}$ & $15.48 \pm 0.37^{\mathrm{c}}$ & $10.34 \pm 0.10^{\mathrm{ab}}$ \\
$\mathbf{4 .}$ & Black beans & $16.59 \pm 0.70^{\mathrm{c}}$ & $15.70 \pm 0.44^{\mathrm{c}}$ & $9.25 \pm 0.05^{\mathrm{ab}}$ \\
$\mathbf{5 .}$ & Purple sweet potatoes & $22.93 \pm 0.35^{\mathrm{d}}$ & $17.04 \pm 0.41^{\mathrm{c}}$ & $7.7 \pm 0.11^{\mathrm{a}}$ \\
$\mathbf{6 .}$ & Mung beans & $30.47 \pm 0.80^{\mathrm{e}}$ & $14.97 \pm 1.24^{\mathrm{c}}$ & $8.85 \pm 0.11^{\mathrm{a}}$ \\
7. & Green bananas & $48.29 \pm 0.66^{\mathrm{f}}$ & $19.60 \pm 2.34^{\mathrm{b}}$ & $9.31 \pm 1.01^{\mathrm{ab}}$ \\
$\mathbf{8 .}$ & Potato starch & $56.43 \pm 0.78^{\mathrm{g}}$ & $21.05 \pm 0.71^{\mathrm{b}}$ & $14.72 \pm 0.04^{\mathrm{b}}$ \\
\hline
\end{tabular}

Values are expressed as the mean $\pm \mathrm{SD}$. Values with different superscripts are significantly different per column $(p<0.05)$. RS: Resistant starch 
starch, green bananas, mung beans, and purple sweet potatoes had $9.25 \%, 9.46 \%, 9.31 \%, 8.85 \%$, and $7.7 \%$, respectively. The moisture content was used in calculating the RS content.

\subsection{Amylose Content}

The amylose content in starchy foods affects starch digestion rate, blood glucose, and insulin responses to these starchy foods [29] because amylose polymers have less surface area and more intramolecular hydrogen bonds, decreasing accessibility of $\alpha$-amylase to the molecules. The ratio of the two major polysaccharide components, amylose and amylopectin, affects the textural and thermodynamic characteristics of a particular starch [30]. The principle involved in the determination of apparent amylose content was based on the ability of amylose to bind to iodine, giving a blue color complex. The reaction was monitored using a spectrophotometer to measure the absorption of light [10]. The amylose content of the samples was significantly different $(p<0.05)$ between samples. The results in Table 1 presented the amylose content of potato starch and corn starch to be $21.05 \%$ and $24.73 \%$, respectively. The amylose contents of yellow sweet potatoes, green bananas, purple sweet potatoes, black beans, and red kidney beans were $20.04 \%, 19.60 \%, 17.04 \%, 15.70 \%$, and $15.48 \%$, respectively. The lowest amylose content was in mung beans at $14.97 \%$. The content of amylose in potato starch obtained was slightly higher than the $17 \%$ obtained by Rosin et al. [31] and $18 \%$ by Svegmark et al. [32] but it was comparable with Vasanthan et al. [33] at $19 \%-24 \%$. In another study, Jansky et al. [34] obtained a range of $25 \%-30 \%$ amylose content in several varieties of potato tubers. The amylose content of corn starch obtained in the current study differed from that determined by the study by Mir et al. [35] where they obtained a range of between $24.74 \%$ and $30.32 \%$ of amylose content. In a different study, the amylose content of corn starch was $24.8 \%$ and potato starch $20.5 \%$ [36] which were also comparable with this study. The amylose content of green bananas was slightly lower than the results obtained by Li et al. [37] with $21.3 \%$ amylose content. However, the study carried out by Ravi et al. [38] obtained different results of amylose content in green bananas with the highest being $36.87 \%$ on one cultivar. Soison et al. [39] found slightly lower results of amylose content in yellow sweet potatoes but similar results for purple sweet potatoes ranging from $16.5 \%$ to $18.5 \%$ compared with the current study. Black beans were found to have the highest amylose content at $45.4 \%$ and red kidney beans at $32.4 \%$ [40], which were extremely high compared to the current study. Hoover et al. [41] also recorded high amylose content in beans of between $21.2 \%$ and $65 \%$. The amylose content of mung bean flour in a study by Kaur et al. [42] was high at $29.9 \%-33.6 \%$ compared to this study. The difference in amylose content of the tested samples in this study from that reported in the previous study may have resulted due to different growing regions and conditions. Figure 1 shows a relationship between the RS content and the amount of amylose in a specific sample.

\subsection{Swelling Capacity}

Swelling capacity represents the measure of the ability of starch to absorb water and swell in various starch materials [43]. It provides evidence of interactions between the water molecules and the starch chains in the crystalline and amorphous region of the starch. Several factors affect the swelling power of starch powders such as amylose,

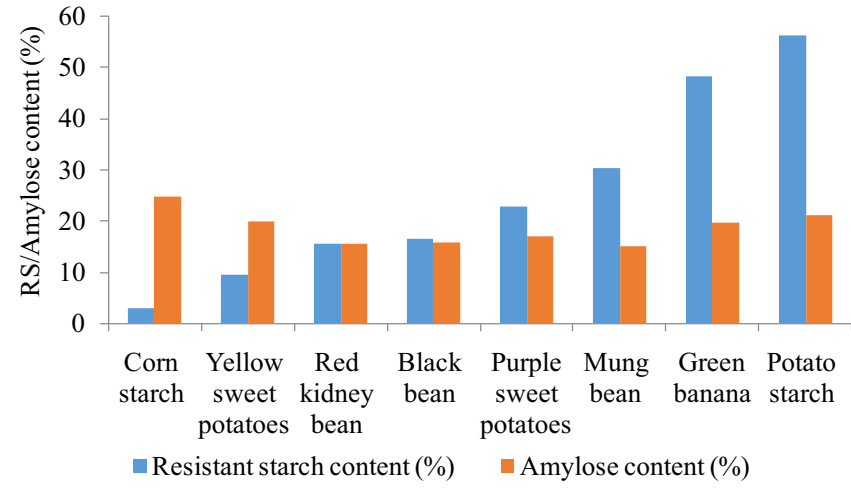

Figure 1: RS and amylose contents in starchy food sources.

protein, lipids, amylopectin, and particle size [44]. Amylose may strengthen the internal network and reduce the swelling ability of starch powder due to interassociative forces within the amorphous and crystalline domains [45]. The results obtained showed a significant difference $(p<0.05)$ in the swelling power of samples when analyzed by ANOVA. Yellow sweet potatoes and purple sweet potatoes had high swelling powers of 8.47 and $7.97 \mathrm{~g} / \mathrm{g}$, respectively, while mung beans, red kidney beans, black beans, and green bananas recorded 6.97, 5.49, 5.47 and $3.99 \mathrm{~g} / \mathrm{g}$, respectively. Corn starch and potato starch had the least swelling of $1.49 \mathrm{~g} / \mathrm{g}$ each (Table 2). A study carried out by Kusumayanti et al. [45] found lower swelling power in purple sweet potatoes of $3.67 \mathrm{~g} / \mathrm{g}$ and yellow sweet potatoes of $3.57 \mathrm{~g} / \mathrm{g}$ compared to this study. The difference resulted from different sources of sweet potatoes and pretreatment (blanching) applied to sweet potatoes in the current study before measuring the swelling. Twelve varieties of Ghanian sweet potatoes obtained a range of swelling power between 4.6 and $5.9 \mathrm{~g} / \mathrm{g}$ with a significant difference $(p<0.001)$ [30] which was still slightly lower than the results in this study.

Ratnawati et al. [46] obtained a slightly high amount of swelling power for mung beans and red kidney beans at 10.52 and 10.09 $\mathrm{g} / \mathrm{g}$, respectively, compared to the results of the current study. There was a similarity in the results obtained by Pragati et al. [47] of $3.57 \mathrm{~g} / \mathrm{g}$ swelling power of green bananas at $3.99 \mathrm{~g} / \mathrm{g}$ in this research. Blanching of purple sweet potatoes and yellow sweet potatoes before grinding to powder may have caused leaching of amylose which contributed to the high number of hydrogen bonds formed between the very long-branch chains of amylopectin and water, which led to high swelling power of the two sweet potatoes [44] and high water retention capacity as well as increasing the gel structure of starch powder [47].

Potato and corn starches are solubilized in distilled water, which made it difficult to measure the swelling capacity and WAC of the two samples. Despite that, it was found that the RS content in potato starch was very high with a 55.88/100 g dry weight basis while that of corn starch was the least with a $2.8 / 100 \mathrm{~g}$ dry weight basis. Therefore incorporating potato starch into food products such as noodles could improve RS consumption of individuals while corn starch can be used for functional properties not because of RS content. The reason for blanching was to retain the desirable color of sweet potatoes. The pregelatinized sweet potatoes had a swelling capacity higher than native sweet 
Thuy et al.: Resistant starch in various starchy vegetables and the relationship with its physical and chemical characteristics 2022;10(01):181-188

Table 2: Swelling capacity, water absorption capacity and resistant starch of starchy food sources

\begin{tabular}{lcccc} 
& Samples & Swelling capacity $(\mathrm{g} / \mathbf{g})$ & WAC $(\mathrm{g} / \mathbf{g})$ & $\begin{array}{c}\text { RS content } \\
(\mathbf{g} / \mathbf{1 0 0 g})\end{array}$ \\
1. & Corn starch & $1.49 \pm 0.01^{\mathrm{a}}$ & $0.0^{\mathrm{a}}$ & $2.82 \pm 0.00^{\mathrm{a}}$ \\
2. & Yellow sweet potatoes & $8.47 \pm 0.02^{\mathrm{b}}$ & $4.87 \pm 0.26^{\mathrm{b}}$ & $9.44 \pm 1.87^{\mathrm{b}}$ \\
3. & Red kidney beans & $5.49 \pm 0.70^{\mathrm{c}}$ & $1.48 \pm 0.09^{\mathrm{c}}$ & $15.54 \pm 0.51^{\mathrm{c}}$ \\
4. & Black beans & $5.46 \pm 0.72^{\mathrm{c}}$ & $2.11 \pm 0.20^{\mathrm{d}}$ & $16.59 \pm 0.70^{\mathrm{d}}$ \\
5. & Purple sweet potatoes & $7.97 \pm 0.01^{\mathrm{b}}$ & $4.63 \pm 0.10^{\mathrm{b}}$ & $22.93 \pm 0.35^{\mathrm{e}}$ \\
6. & Mung beans & $6.96 \pm 0.70^{\mathrm{d}}$ & $1.57 \pm 0.43^{\mathrm{cd}}$ & $30.47 \pm 0.80^{\mathrm{f}}$ \\
7. & Green bananas & $3.99 \pm 0.00^{\mathrm{e}}$ & $1.75 \pm 0.00^{\mathrm{cd}}$ & $48.29 \pm 0.66^{\mathrm{g}}$ \\
$\mathbf{8 .}$ & Potato starch & $1.49 \pm 0.01^{\mathrm{a}}$ & $0.0^{\mathrm{a}}$ & $56.43 \pm 0.78^{\mathrm{h}}$ \\
\hline
\end{tabular}

Values are expressed as the mean $\pm \mathrm{SD}$. Values with different superscripts are significantly different per column $(p<0.05)$ WAC: Water Absorption Capacity, RS: Resistant starch

potatoes, probably because the increase in swelling was related to the increasing amount of amylose and amylopectin leaching of the starch granules [48]. A high amylose content in potato starch and corn starch powders led to very low swelling power as shown in Table 2 on amylose content. The protein content in the flour samples may have resulted in lower swelling power by being embedded in the starch granules forming a stiff matrix that limits water access into the granules [44]. As shown in Figure 2, the negative correlation between RS content and swelling capacity was observed. Potato starch which had the highest RS content recorded the least swelling while yellow sweet potatoes with one of the least RS recorded the highest swelling power.

\subsection{Water Absorption Capacity}

WAC is useful in determining the ability of flour to take up water and swell and improve the quality of food. It is of importance to food processing as it improves the yield of food, the shape of food and uniformity of the food products [49]. The results showed that yellow sweet potatoes and purple sweet potatoes had the highest water absorption capacities of 4.8 and $4.6 \mathrm{~g} / \mathrm{g}$, respectively, followed by black beans with $2.1 \mathrm{~g} / \mathrm{g}$, and the least amount of WAC was recorded by green bananas, mung beans, and red beans in a decreasing order of $1.74,1.57$, and $1.48 \mathrm{~g} / \mathrm{g}$, respectively. There was no significant difference in the mean of the WAC of red kidney beans, mung beans,

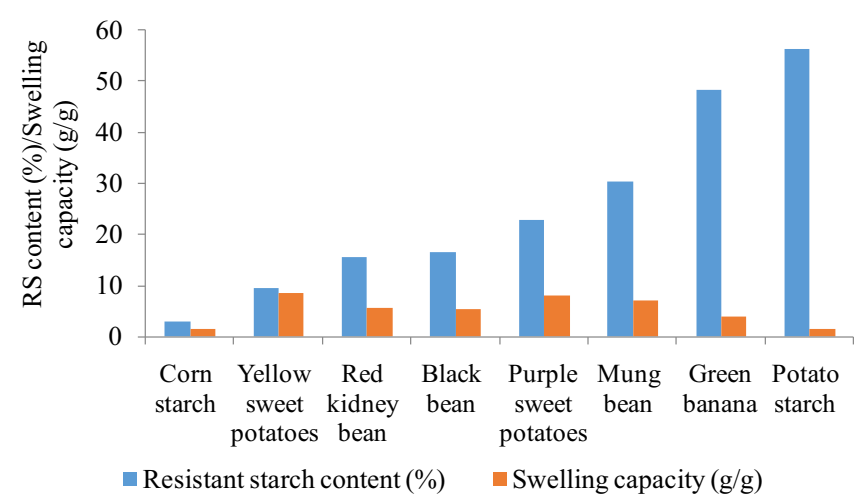

Figure 2: Effect of RS content on swelling power of starchy foods. and green bananas, while black beans had no significant difference in WAC compared to mung beans and green bananas. However, the results of the WAC of yellow sweet potatoes and purple sweet potatoes were comparable. In comparison to the results in Table 2 (as mentioned above), Ngoma et al. [49] found the WAC of pretreated sweet potatoes was significantly $(p<0.05)$ high at 1.63 to $2.03 \mathrm{ml} / \mathrm{g}$ compared to the control sample at $1.44 \mathrm{ml} / \mathrm{g}$ but the results were generally very low compared to this study. The high WAC recorded for yellow sweet potatoes and purple sweet potatoes may have resulted from high polar amino acids residue of proteins having a high affinity for water molecules. Carbohydrates and proteins have hydrophilic parts which are charged side chains and polar sides; therefore, they are major constituents which increase the WAC of flours [49]. The water absorption capacities of mung beans and red kidney beans were 3.18 and $4.39 \mathrm{~g} / \mathrm{g}$, respectively, according to Ratnawati et al. [46], which were slightly higher than the results obtained in this study. The results of the WAC of green bananas of $1.74 \mathrm{~g} / \mathrm{g}$ in Table 2 were consistent with those reported by Fontes et al. [50] for green bananas of $1.19 \mathrm{~g} / \mathrm{g}$. Figure 3 shows the relationship between WAC and RS content. It is evident that the WAC has a negative correlation with RS content. The samples high in RS had the lowest WAC. The swelling power showed a similar trend to WAC with yellow sweet potatoes and purple sweet potatoes recording the highest value while potato

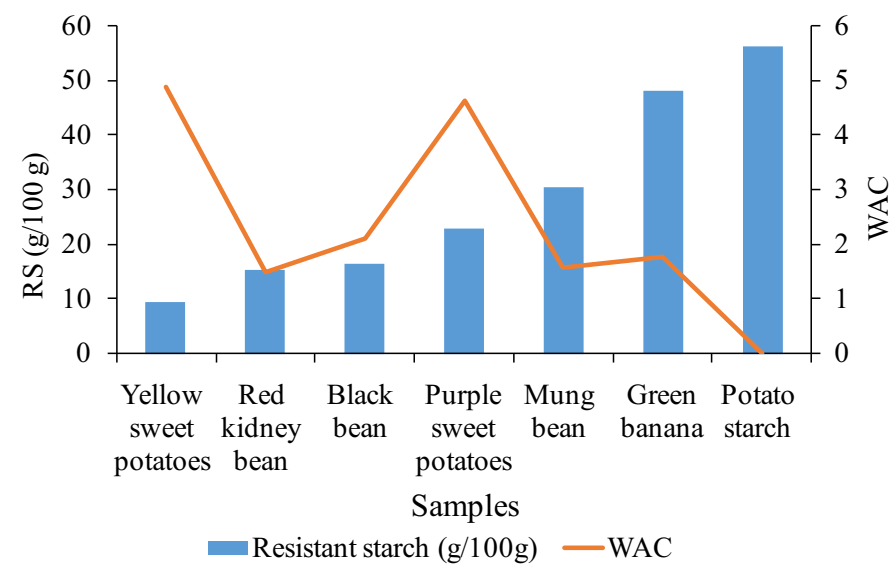

Figure 3: Relationship between WAC and RS. 

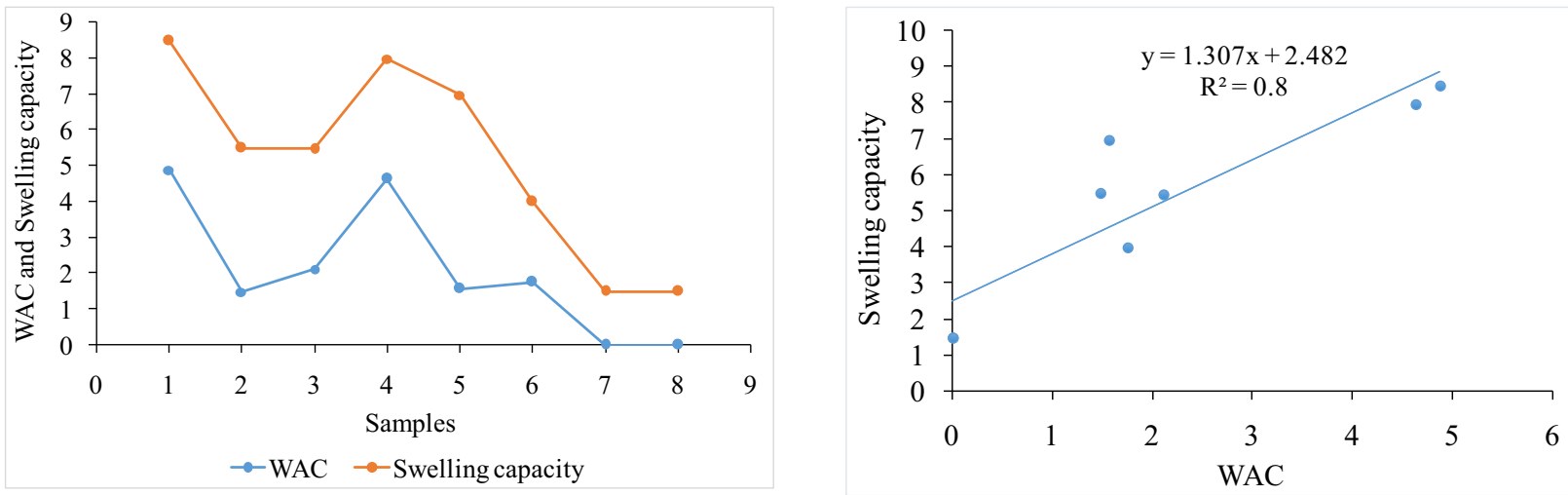

Figure 4: Relationship between swelling and WAC of samples.

starch and corn starch recorded the lowest values; these values were consistent with results obtained by Hernández-Fernández et al. [51] on the impact of fertilization on physicochemical and functional properties of cassava starch. Swelling and WAC were correlated since swelling was influenced by the ability of starch to bind with water molecules through hydrogen bonding. The increased swelling of the starch granules rupture is caused by intermolecular hydrogen bonding in the area of amorphous regions occurring at temperatures below $70^{\circ} \mathrm{C}$ [48]. The strong correlation of swelling power and WAC is shown in Figure 4.

\section{CONCLUSION}

The amylose content of starchy food had a strong correlation with $\mathrm{RS}$, and the high amount of amylose resulted in a high amount of RS content in food attributed to the linear chain of amylose that resists digestion by pancreatic enzymes. On the other hand, swelling power had an inverse relationship with RS content with foods high in RS depicting low swelling power and low WAC. These properties of low swelling power and low WAC are undesirable in food processing; therefore, a balance in the proportion of RS sources ought to be found before replacing it in formulations used to make food products.

\section{AUTHOR CONTRIBUTIONS}

All authors made substantial contributions to conception and design, acquisition of data, or analysis and interpretation of data; took part in drafting the article or revising it critically for important intellectual content; agreed to submit to the current journal; gave final approval of the version to be published; and agree to be accountable for all aspects of the work. All the authors are eligible to be an author as per the international committee of medical journal editors (ICMJE) requirements/guidelines.

\section{FUNDING}

There is no funding to report.

\section{CONFLICTS OF INTEREST}

The authors report no financial or any other conflicts of interest in this work.

\section{ETHICAL APPROVALS}

This study does not involve experiments on animals or human subjects.

\section{PUBLISHER'S NOTE}

This journal remains neutral with regard to jurisdictional claims in published institutional affiliation.

\section{REFERENCES}

1. SajilataMG, SinghalRS, KulkarniPR.Resistantstarch-areview.Compr Rev Food Sci Food Saf 2006;5:1-7; doi:10.1111/j.1541-4337.2006. tb00076.x

2. Dupuis HJ, Qiang L, Rickey YY. Methodologies for increasing resistant starch of food starch. A review. Compr Rev Food Sci Food Saf 2014;13(6):1219-34; doi:10.1111/1541-4337.12104

3. Garg NK, Singh A, Chaudhary DP. Resistant starch: a potential impact on human health. Int J Curr Microbiol Appl Sci 2017;6(5):2046-57; doi:10.20546/ijcmas.2017.605.228

4. Fuentes-Zaragoza E, Riquelme-Navarrete MJ, Sánchez-Zapata E, Pérez-Álvarez JA. Resistant starch as functional ingredient: a review. Food Res Int 2010;43(4):931-42; doi: 10.1016/j. foodres.2010.02.004

5. Nugent AP. Health properties of resistant starch. Nutr Bull 2005;30(1):27-54; doi:10.1111/j.1467-3010.2005.00481.x

6. Hasjim J, Ai Y, Jane JL. Novel applications of amylose-lipid complex as resistant starch type 5. In: Shi YC, Maningat CC (eds.). Resistant starch, Chapter 4, John Wiley \& Sons, Hoboken, New Jersey, pp 7994, 2013; doi:10.1002/9781118528723.ch4

7. Thuy NM, Chi NTD, Huyen THB, Tai NV. Orange-fleshed sweet potato grown in Viet Nam as a potential source for making noodles. Food Res 2020;4(3):712-21; doi:10.26656/fr.2017.4(3).390

8. Ang PT. Adaptation and Validation of Existing Analytical Methods for Monitoring Prebiotics Present in Different Types of Processed Food Matrices. Lincoln, Nebraska: Dissertations, Theses, \& Student Research in Food Science and Technology 2011. Available from: https://digitalcommons.unl.edu/foodscidiss/15.

9. AOAC (Association of Official Analytical Chemists). Official methods of analysis of the Association of Analytical Chemists International. Association of Official Analytical Chemists, Rockville, Maryland, 2005.

10. Ronoubigouwa MAA, Zhongli P, Wada Y, Yoshida T. Two alternative methods to predict amylose content in rice grain by using tristimulus CIELAB values and developing a specific color board of starch-iodine complex solution. In Abstracts of Meeting of 
the CSSJ The 229th Meeting of the Crop Science Society of Japan. 2010, p 376.

11. Nyam KL, Leao SY, Tan CP, Long K. Functional properties of roselle (Hibiscus sabdariffa L.) seed and its application as bakery product. $\mathrm{J}$ Food Sci Technol 2014;51(12): 3830-7.

12. Chen L, Liu R, Qin C, Meng Y, Zhang J, Wang Y, et al. Sources and intake of resistant starch in the Chinese diet. Asia Pac J Clin Nutr 2010;19(2):274.

13. Moongngarm A, Tiboonbun W, Sanpong M, Sriwong P, Phiewtong $\mathrm{L}$, Prakitrum R, et al. Resistant starch and bioactive contents of unripe banana flour as influenced by harvesting periods and its application. Am J Agri Biol Sci 2014;9(3):457-65; doi:10.3844/ ajabssp.2014.457.465

14. Langkilde AM, Champ M, Andersson H. Effects of high-resistantstarch banana flour (RS2) on in vitro fermentation and the small-bowel excretion of energy, nutrients, and sterols: an ileostomy study. Am J Clin Nutr 2002;75(1):104-11; doi:10.1093/ajcn/75.1.104

15. Englyst HN, Kingman SM, Cummings JH. Classification and measurement of nutritionally important starch fractions. Eur J Clin Nutr 1992;46 (suppl):S33-50.

16. Fabbri AD, Schacht RW, Crosby GA. Evaluation of resistant starch content of cooked black beans, pinto beans, and chickpeas. NFS J 2016;3:8-12; doi:10.1016/j.nfs.2016.02.002

17. Silva-Crystobal L, Osorio-Díaz P, Tovar J, Bello-Pérez LA. Chemical composition, carbohydrate digestibility, and antioxidant capacity of cooked black bean, chickpea, and lentil Mexican varieties composiciónquímica, digestibilidad de carbohidratos, y capacidadantioxidante de variedadesmexicanascocidas de frijol negro, garbanzo, y lenteja. Cyta J Food 2010;8(1):7-14; doi:10.1080/19476330903119218

18. Reddy CK, Suriya M, Haripriya S. Physico-chemical and functional properties of resistant starch prepared from red kidney beans (Phaseolus vulgaris. L) starch by enzymatic method. Carbohydr Polym 2013;95(1):220-6; doi:10.1016/j.carbpol.2013.02.060

19. Moongngarm A. Chemical compositions and resistant starch content in starchy foods. Am J Agric Biol Sci 2013;8(2):107; doi: 10.3844/ ajabssp.2013.107.113

20. Eashwarage IS, Herath HMT, Gunathilake KGT. Dietary fibre, resistant starch and in-vitro starch digestibility of selected eleven commonly consumed legumes (mung bean, cowpea, soybean and horse gram) in Sri Lanka. Res J Chem 2020;7(2):1-7.

21. Zheng Y, Wang Q, Li B, Lin L, Tundis R, Loizzo MR, et al. Characterization and prebiotic effect of the resistant starch from purple sweet potato. Mol 2016;21(7):932; doi:10.3390/ molecules21070932

22. Yea CS, Nevara GA, Muhammad K, Ghazali HM, Karim R. Physical properties, resistant starch content and antioxidant profile of purple sweet potato powder after 12 months of storage. Int J Food Prop 2019;22(1):974-84; doi:10.1080/10942912.2019.1620765

23. Senanayake SA, Ranaweera KKDS, Gunaratne A, Bamunuarachchi A. Comparative analysis of nutritional quality of five different cultivars of sweet potatoes (Ipomeabatatas (L) Lam) in Sri Lanka. Food Sci Nutr 2013;1(4):284-91; doi:10.1002/fsn3.38

24. Kim HJ, Woo KS, Lee HU, Nam SS, Lee BW, Kim MY, et al. Physicochemical characteristics of starch in sweet potato cultivars grown in Korea. Prev Nutr Food Sci 2020;25(2):212; doi:10.3746/ pnf.2020.25.2.212

25. Ai Y, Jane JL. Macronutrients in corn and human nutrition. Compr Rev Food Sci Food Saf 2016;15(3):581-98; doi:10.1111/1541-4337.12192

26. Raigond P, Dutt S, Singh B. Resistant starch in food. 2019; doi: 10.1007/978-3-319-78030-6_30

27. Kittipongpatana OS, Kittipongpatana N. Resistant starch contents of native and heat-moisture treated jackfruit seed starch. Scientific World J 2015;2015:519854; doi:10.1155/2015/519854

28. Perera A, Meda V, Tyler RT. Resistant starch, a review of analytical protocols for determining resistant starch and of factors affecting the resistant starch content of foods. Food Res Int 2010;43:1959-74; doi:10.1016/j.foodres.2010.06.003

29. Mir JA, Srikaeo K, García J. Effects of amylose and resistant starch on starch digestibility of rice flours and starches. Int Food Res J 2013;20(3):1329-35

30. Tortoe C, Akonor PT, Koch K, Menzel C, Adofo K. Physicochemical and functional properties of flour from twelve varieties of Ghanaian sweet potatoes. Int Food Res J 2017;24(6):2549-56.

31. Rosin PM, Lajolo FM, Menezes EW. Measurement and characterization of dietary starches. J Food Compost Anal 2002;15(4):36777; doi:10.1006/jfca.2002.1084

32. Svegmark K, Helmersson K, Nilsson G, Nilsson PO, Andersson R, Svensson E. Comparison of potato amylopectin starches and potato starches-influence of year and variety. Carbohydr Polym 2002;47(4):331-40; doi:10.1016/S0144-8617(01)00174-6

33. Vasanthan T, Bergthaller W, Driedger D, Yeung J, Sporns P. Starch from Alberta potatoes: wet-isolation and some physicochemical properties. Food Res Int 1999;32(5):355-65; doi:10.1016/S09639969(99)00096-4

34. Jansky S, Fajardo D. Amylose content decreases during tuber development in potato. J Sci Food Agri 2016;96(13):4560-4; doi: $10.1002 /$ jsfa. 7673

35. Mir SA, Bosco SJD, Bashir M, Shah MA, Mir MM. Physicochemical and structural properties of starches isolated from corn cultivars grown in Indian temperate climate. Int J Food Prop 2017;20(4):821-32; doi: 10.1080/10942912.2016.1184274

36. Domene-López D, García-Quesada JC, Martin-Gullon I, Montalbán MG. Influence of starch composition and molecular weight on physicochemical properties of biodegradable films. Polym 2019;11(7):1084; doi:10.3390/polym11071084

37. Li Z, Guo K, Lin L, He W, Zhang L, Wei C. Comparison of physicochemical properties of starches from flesh and peel of green banana fruit. Mol 2018;23(9):2312; doi:10.3390/molecules23092312

38. Ravi I, Mustaffa MM. Starch and amylose variability in banana cultivars. Indian J Plant Physiol 2013;18(1):83-7; doi:10.1007/ s40502-013-0014-2

39. Soison B, Jangchud K, Jangchud A, Harnsilawat T, Piyachomkwan K. Characterization of starch in relation to flesh colors of sweet potato varieties. Int Food Res J 2015;22(6):2302.

40. Du SK, Jiang H, Ai Y, Jane JL. Physicochemical properties and digestibility of common bean (Phaseolus vulgaris L.) starches. Carbohydr Polym 2014;108:200-5; doi:10.1016/j.carbpol.2014.03.004

41. Hoover R, Sosulski FW. Composition, structure, functionality, and chemical modification of legume starches: a review. Can J Physiol Pharmacol 199;69(1):79-92; doi:10.1139/y91-012

42. Kaur M, Sandhu KS, Singh N, Lim ST. Amylose content, molecular structure, physicochemical properties and in vitro digestibility of starches from different mung bean (Vignaradiata L.) cultivars. StarchStärke 2011;63(11):709-16; doi:10.1002/star.201100053

43. Ojo MO, Ariahu CC, Chinma EC. Proximate, functional and pasting properties of cassava starch and mushroom (Pleurotus pulmonarius) flour blends. Am J Food Sci Technol 2017;5(1):11-8; doi:10.12691/ ajfst-5-1-3.

44. Aprianita A, Vasiljevic T, Bannikova A, Kasapis S. Physicochemical properties of flours and starches derived from traditional Indonesian tubers and roots. J Food Sci Technol 2014;51(12):3669-79; doi:10.1007/s13197-012-0915-5

45. Kusumayanti H, Handayani NA, Santosa H. Swelling power and water solubility of cassava and sweet potatoes flour. Proc Environ Sci 2015;23:164-7; doi:10.1016/j.proenv.2015.01.025

46. Ratnawati L, Desnilasari D, Surahman DN, Kumalasari R. Evaluation of physicochemical, functional and pasting properties of soybean, mung bean and red kidney bean flour as ingredient in biscuit. In IOP Conference Series: Earth and Environmental Science IOP Publishing, 2019, 251(1), p 012026; doi:10.1088/1755-1315/251/1/012026 
47. Pragati S, Genitha I, Ravish K. Comparative study of ripe and unripe banana flour during storage. J Food Process Technol 2014;5(11):1; doi:10.4172/2157-7110.1000384

48. Marta H, Tensiska T. Functional and amylographic properties of physically-modified sweet potato starch. KnE Life Sci 2017;689-700; doi:10.18502/k1s.v2i6.1091

49. Ngoma K, Mashau ME, Silungwe H. Physicochemical and functional properties of chemically pretreated ndou sweet potato flour. Int J Food Sci 2019;2019:1-9; doi:10.1155/2019/4158213

50. Fontes SDM, Cavalcanti MT, Candeia RA, Almeida EL. Characterization and study of functional properties of banana starch green variety of Mysore (Musa AAB-Mysore). Food Sci Technol 2017;37(2):224-31; doi:10.1590/1678-457x.18916

51. Hernández-Fernández N, Adriano-Anaya L, Salvador-Figueroa $\mathrm{M}$, Betancur-Ancona D, Vázquez-Ovando A. Impact of organic fertilization on physicochemical and functional properties of cassava starch. Starch-Stärke 2016;68(5-6): 549-57; doi:10.1002/ star.201500257

How to cite this article:

Thuy NM, Too BC, Vuong KM, Lan PTT, Tuyen PTT,

Tram NB, Vy LTT, Tuyen LN, Tai NV. Resistant starch

in various starchy vegetables and the relationship with its physical and chemical characteristics. J Appl Biol Biotech 2022;10(01):181-188. 